\title{
An Investigation into Morphological and Physiological Approaches to Screen Maize (Zea mays L.) Hybrids for Drought Tolerance
}

\author{
M. ASLAM, M.S.I. ZAMIR, S.A. ANJUM*, I. KHAN and M. TANVEER \\ Department of Agronomy, University of Agriculture, Faisalabad, Pakistan
}

(Received 4 November 2013; Accepted 28 March 2014)

\begin{abstract}
A pot experiment was carried out in completely randomized design (CRD) having three replications to screen out six maize (Zea mays L.) hybrids viz; FH-810, 32-F-10, FH-782, 32-B-33, YH-1898, Monsanto-6525, R-2315 and R-3304 for drought tolerance. The study was carried out with objective to screen hybrids, when exposed to drought on the early phase of their vegetative growth. The moisture treatments comprised of $100 \%$ field capacity (FC), $75 \%$ FC and $50 \%$ FC. The results exhibited that all these hybrids varied substantially in their stability against drought tolerance. However, the results pertaining to interaction of maize hybrids with three moisture levels of $100 \% \mathrm{FC}, 75 \% \mathrm{FC}$ and $50 \% \mathrm{FC}$ revealed that $32-\mathrm{F}-10$ performed comparatively better in contrast to other maize hybrids in plant height $(79.74 \mathrm{~cm}, 47.02 \mathrm{~cm}$ and $41.65 \mathrm{~cm})$, leaf area per plant $\left(865.10 \mathrm{~cm}^{2}, 405.7 \mathrm{~cm}^{2}\right.$ and $\left.178.60 \mathrm{~cm}^{2}\right)$, relative water contents $(81.23 \%, 69.79 \%$ and $65.98 \%$ ), at $100 \%, 75 \%$ and $50 \% \mathrm{FC}$, respectively, while YH-1898 hybrid produced lowest values of these attributes in almost all water levels. However, a better stomatal conductance $(\mathrm{gs})$, photosynthetic rate $(\mathrm{A})$ and transpiration rate $(\mathrm{E})$ were exhibited by 32-F-10 while YH-1898 revealed least gas-exchange values among all hybrids. The experimental results revealed that under drought conditions 32-F-10 performed best than all other maize hybrids and could be used for further investigation to screen out other drought tolerant-maize hybrids for maximum production.
\end{abstract}

Keywords: maize, drought tolerance, hybrids, photosynthesis, stomatal conductance

\section{Introduction}

The planet 'Earth' is facing a scarcity of fresh water supply and concomitant with a disquieting threat to agriculture production in the near future. Maize (Zea mays L.) is an important cereal, bears remarkable importance in food security. Maize yields for the 2012-13 growing season decreased approximately 13 percent in comparison to 2011, for a total production of 274.3 million tons (FAO 2012). This declining trend in production potential might be attributed to numerous key production factors, including ground water which is turning out to be exhausted owing to climate change and alteration in precipitation patterns, thus resulted in lack of ample moisture supply for sustainable crop production.

* Corresponding author; E-mail: shakeelanjum1034@yahoo.com 
Global warming has resulted in long-term fluctuations in climatic parameters, encompasses high temperature, long-lasting drought and high evapo-transpiration. These trends when coupled with maize production on marginal lands lead to increasingly drought prevalence. Drought being an abiotic stress may trigger a deficiency of food for the present and future generations (Somerville and Briscoe 2001). In the entire globe, drought is very alarming hazard for crop production as it causes a deficit moisture situation for plant growth and development (Anjum et al. 2011d). Drought being a major physiological mechanism reduces almost $50 \%$ yield of crop plants (Wang et al. 2003). The consequences of severe drought stress are; reduction in leaf size, stem elongation and root anchorage which disturb the metabolic activities and water use efficiency of crop plants (Farooq et al. 2009). For the initiation of plant body growth, cell division, enlargement and differentiation are the obligatory components. Under drought stress the cell generally shrinks and reduces its volume making its solutes more viscous which can be detrimental to photosynthetic mechanism (Hoekstra et al. 2001). Drought stress disturbs physiological and biochemical processes and consequently, diminishes growth and yield (Farooq et al. 2008). Reduction of water contents in plant body parts, leaf water potential loss and loss of turgor, stomatal closure and decrease in cell enlargement and growth are the main consequences of drought during the initial stage, however severe drought disrupts photosynthesis, arrest metabolism and eventually results in plant death (Anjum et al. 2011a, d).

The uses of genetics in order to improve drought tolerance endows with yield stability (Duvick 2005), is a considerable part of solution and approaches to enhance maize production during drought. However, it takes time to develop a drought tolerant cultivar due to stress heterogeneity in fields rather contrarily climate is changing with more pace and severity. Under such scenario, it will be quite economical and time saving approach to screen various cultivars using morphological, physiological and biochemical indicators rather than to go for final yield analysis in breeding programs. Final yield is a function of growth, plant with good growth and development results in more economical yield. The seeds of improved germplasm have shown itself to be effective mean of transferring drought tolerant traits. Thus in order to improve drought tolerance and screening the existing germplasms for future drought resistance breeding programs, understanding between genotype and phenotype response and also their interaction response to array of changing environmental conditions especially drought could be a better outreach to develop or induce drought tolerance in new or conventional germplasms, respectively. It is well documented that physiological and morphological characteristics such as osmotic adjustment, stomatal behaviour, chloroplast activity, leaf water potential, root volume, root weight, leaf area and dry matter production are found different in maize cultivars grown under limited water supply (Anjum et al. 2011a). Moreover, research work on maize crop showed that water deficit in the root zone reduced the leaf area, chlorophyll contents and photosynthesis rate (Athar and Ashraf 2005).

Maize is considered drought sensitive crop, however vigorous seedling can provide a good crop stand and hence productivity. Drought has deleterious effects on seedling stage as well as on its growth and development (Delachiave and De Pinho 2003). Maize plants having more roots at seedling stage develop extensive root system and produce greener 
biomass. In order to improve the drought tolerance in maize hybrids; there is dire need to reduce loss of water from the leaves. Tambussi et al. (2007) presented a fine idea that reduction of leaf area and its size is the important phenomenon to diminish the loss of water from leaves canopy. Leaf temperature has greater impact on the transpiration rate. Leaf surface has epicutical wax and hairs reduce transpiration (E) without reducing photosynthesis (A) and stomatal conductance ( $g_{s}$ ) (Anjum et al. 2011c). The current study was carried out with aim to screen six maize hybrids at their early growth stages by taking morphological and physiological attributes as study traits.

\section{Materials and Methods}

The experiment was conducted at Postgraduate Agricultural Research Station (PARS), University of Agriculture Faisalabad Pakistan. The station is located between longitude $73^{\circ}-74^{\circ}$ East, latitude $30^{\circ}-31.5^{\circ}$ North, with an elevation of 184 meters above sea level. The soil was sandy loam and alluvial in nature and contained $0.37 \%$ organic matter, $55 \%$ sand, $22 \%$ silt, $23 \%$ clay particles. Further, its EC was $0.71 \mathrm{dSm}^{-1}$, wilting point $8.2 \%$, field capacity $25.4 \%$ and sodium absorption ratio $9 \%$.

\section{Determination of field capacity (FC)}

The FC was determined on gravimetric basis (Nachabe 1998). For determination of FC three samples of $200 \mathrm{~g}$ each of the soil used in the experiment were taken at the time of filling the earthen pots. These samples were then incubated at $105^{\circ} \mathrm{C}$ for 24 hours. These oven dried samples were weighed and averaged for determination of total moisture contents of the soil at the time of seed sowing. Then the saturation percentage of three samples of 100 $\mathrm{g}$ each of this oven dried soil was approximated by measuring and then averaging the distilled water used in making completely saturated paste of three samples. The FC was determined by using the following formulae:

$$
\text { Field capacity }=\text { Saturation percentage } \div 2
$$

Field capacity of each pot was maintained as per treatment. Soil moisture percentage of each pot was measured on daily basis with the help of SM-200 soil moisture sensor (Delta-T device, Cambridge, UK). This sensor first creates a $100 \mathrm{MHz}$ waveform, when power is applied. The waveform is applied to a pair of stainless steel rods which transmit an electromagnetic field into the soil. These rods then detect the permittivity of soil and soil moisture, results in a stable voltage output that acts as a simple, sensitive measure of soil moisture content. Its measurement ranges 0 to $1.5 \mathrm{~m}^{3} \mathrm{~m}^{-3}$. Each time the pots were irrigated to maintain the desired field capacity level, when moisture contents were depleted to up to $30 \%$.

\section{Experimental details}

The experiment was conducted in pots in a rain protected wire house. The experiment was laid out in Completely Randomized Design (CRD) with three replications. The experi- 
mental treatments were as follows; maize hybrids (FH-810, 32-F-10, FH-782, 32-B-33, YH-1898, Monsanto-6525 (6525), R-2315 and R-3304) and moisture levels (100\% field capacity [FC], $75 \% \mathrm{FC}$ and $50 \% \mathrm{FC}$ ). These hybrids were selected on the basis of drought tolerance and sensitiveness by studying their characters narrated by the seed producing organizations. The drought tolerant maize hybrid group was FH-810, 32-F-10, 32-B-33 and 6525 while drought sensitive group was FH-782, YH-1898, R-2315 and R-3304. Further information pertaining to susceptibility to drought stress and thermal time units of these hybrids are given in Table 1. Each pot contains $10 \mathrm{~kg}$ soil. The recommended quantity of fertilizer 250:125:125 kg/ha NPK (1/3 of N was applied as basal dose while remaining N was applied 20 days after sowing) was mixed in ten kilogram of soil on the hectare basis. Eight seeds of each of the hybrid were sown in each pot. The seeds were treated with Amedacloprid and Topsin-M as systemic insecticide and fungicide, respectively.

At four leaf stage thinning was practiced and finally four plants per pot were maintained. drought stress was imposed after two weeks of germination. Crop was uprooted after 35 days of sowing. Morphological parameters like plant height, leaf length, leaf area and stem diameter were determined. Physiological indicators like photosynthetic rate (A), stomatal conductance $\left(\mathrm{g}_{\mathrm{s}}\right)$ and transpiration rate $(\mathrm{E})$ were measured with infrared gas analyzer (Li-6400; Li-Cor, Lincoln, NE, USA). The measurements were done from 8:00 am to 10:00 am with adjustments such as; leaf surface area $12.15 \mathrm{~cm}^{2}$, ambient $\mathrm{CO}_{2}$ concentration 340.72 micromole $\mathrm{mol}^{-1}$, leaf chamber temperature varied from 36.2 to $42.9^{\circ} \mathrm{C}$, gas flow rate of leaf chamber volume $396 \mathrm{~mL} \mathrm{~min}^{-1}$, molar gas flow rate of leaf chamber 251 micromole s ${ }^{-1}$, ambient pressure $99.95 \mathrm{KPa}$, mass flow of air per unit area of leaf chamber $221.06 \mathrm{~mol} \mathrm{~m}^{-2} \mathrm{~s}^{-1}$. For the determination of leaf water potential Scholander type pressure chamber was employed. The third leaf from the top (fully expanded youngest leaf) of maize stem was excised between 6:30 am to 8:30 am for the determination of leaf water potential $\left(\psi_{\mathrm{w}}\right)$ by using Scholander type pressure chamber. The measurement of this parameter was carried out after 35 days of sowing before uprooting of crop. Further, relative water contents (RWCs) regarded as integrated measure of plant water status, was measured by using the following formula (Karrou and Maranville 1995) given below;

$$
\mathrm{RWC}=(\mathrm{FW}-\mathrm{DW}) /(\mathrm{TW}-\mathrm{DW}) \times 100
$$

where FW is the fresh weight of sample, DW is the dry weight of sample and TW is the turgid/soaked weight of sample.

\section{Statistical analysis}

Data collected were analyzed statistically using Fisher's analysis of variance technique. Difference among the treatments means were compared using least significant difference test at $5 \%$ probability level (Steel et al. 1997) using the MSTAT C computer software (MSTAT Development Team 1989). 
Table 1. Susceptibility of hybrids to drought stress and growing degree days (GDD) of maize hybrids

\begin{tabular}{llcr}
\hline Maize hybrid & $\begin{array}{l}\text { Drought and } \\
\text { heat resistant }\end{array}$ & Spring & Autumn \\
\cline { 3 - 4 } FH-810 & Resistant & 115 & 94 \\
$32-$-10 & Resistant & 120 & 100 \\
6525 & Resistant & 115 & 110 \\
$32-B-33$ & Resistant & 116 & 96 \\
YH-1898 & Intermediate & 117 & 102 \\
FH-782 & Intermediate & 112 & 107 \\
R-2315 & Intermediate & 123 & 107 \\
R-3304 & Intermediate & 121 & 109 \\
\hline
\end{tabular}

\section{Results}

\section{Morphological attributes}

Drought stress imposed adverse effects on plant growth. It was noted that maximum plant height was observed at 100\% FC while lowest at 50\% FC (Fig. 1). For the cell division and enlargement, water is required which was more available at $100 \% \mathrm{FC}$ (control) while $75 \%$ and $50 \% \mathrm{FC}$ could not provide the adequate amount of water for apical growth. Thus plant height was less at 75\% FC and 50\% FC. Maize hybrid 32-F-10 produced maximum height at $100 \%$ FC. At $75 \%$ FC it was observed that hybrid 32-F-10 and 6525 produced relatively higher plant height as compare to other hybrids while YH-1898 yielded least height of $47.02 \mathrm{~cm}$. When two maize hybrids such as $32-\mathrm{F}-10$ and R-3304 were submitted to $50 \%$ FC, resulted in enhanced plant height. However, all others were statistically at par with each other. Further, maize hybrid 32-F-10 produced maximum stem diameter while 6525 and R-3304 produced minimum stem diameter (Fig. 1). Drought levels indicated that maximum stem diameter was observed at $100 \%$ FC while minimum stem diameter was observed at $50 \%$ FC. The interaction of maize hybrids and drought levels was significant for leaf length (Fig. 2). It was affirmed from data that at 100\% FC almost all the hybrids produced the leaf length statistically at par except R-3304. At 75\% FC all the hybrids may be categorized into four groups yielded leaf length from highest to lowest. These groups were: (1) 6525, (2) FH-810 which followed a group of hybrids (3) such as 32-F-10, FH-782, 32-B-33 and R-2315 and the final group included (4) R-3304 and YH-1898 (Fig. 2). These groups produced the significantly different leaf length. While at $50 \% \mathrm{FC}$ 32-F-10 produced the maximum leaf length statistically different from other hybrids which were statistically at par among each other. In addition, experimental data indicated that under drought conditions 32-F-10 attained highest leaf area while other hybrids showed similar response towards drought (Fig. 2). 


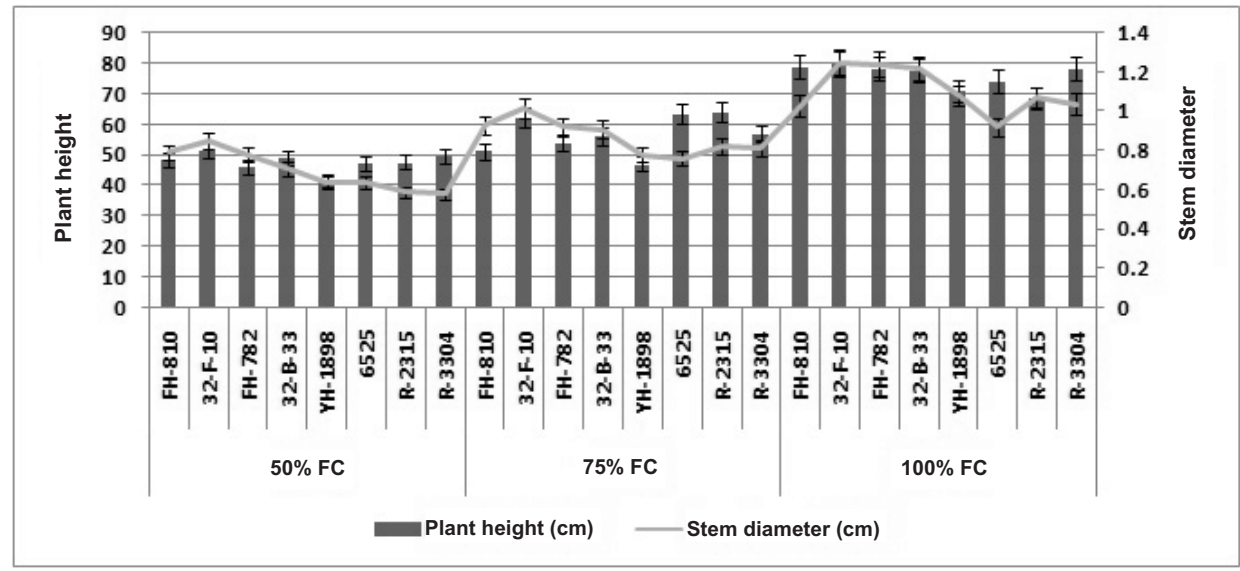

Figure 1. Influence of drought stress on plant height and stem diameter in maize hybrids (mean of three replicates \pm S.E.). Field capacity (FC) levels: $100 \%$ FC, $75 \%$ FC and $50 \%$ FC

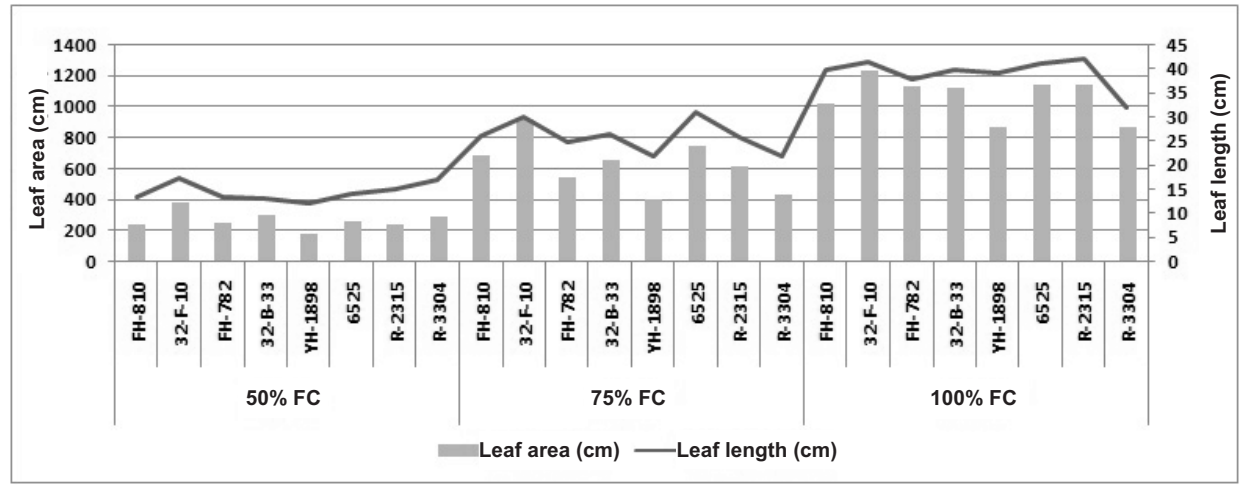

Figure 2. Influence of drought stress on leaf area and leaf length in maize hybrids (mean of three replicates \pm S.E.). Field capacity (FC) levels: $100 \%$ FC, $75 \%$ FC and $50 \%$ FC

\section{Physiological attributes}

Relative water contents (RWC) and leaf water potential (LWP)

The experimental data exhibited that at 100\% FC, hybrid FH-782 yielded the highest RWC (87.26\%) followed by 32-B-33 (84.58\%) while YH-1898 attained least RWC yielded hybrids $(73.39 \%)$. This behaviour was quite different under drought condition (Fig. 3). At 75\% FC the highest RWCs were observed in hybrid 32-F-10 while other hybrids were lesser to it and were statistically at par. However, in the severe drought, at $50 \%$ FC 32-F10 was at the top and YH-1898 at the bottom and others maize hybrids were between them. However, data pertaining to LWP $\left(\Psi_{\mathrm{w}}\right)$ showed that maximum LWP was ob- 
served in two hybrids (32-F-10 and FH-782) at 100\% FC, while all other hybrids developed lesser LWP and the least was recorded in YH-1898. In the mild drought conditions, i.e. at $75 \%$ FC highest LWP was developed by 32-F-10 and the least by YH-1898 (Fig. 3). Similarly, at 50\% FC, 32-F-10 and FH-782 exhibited higher LWP while minimum was recorded in 32-B-33 and YH-1898 (Fig. 3).

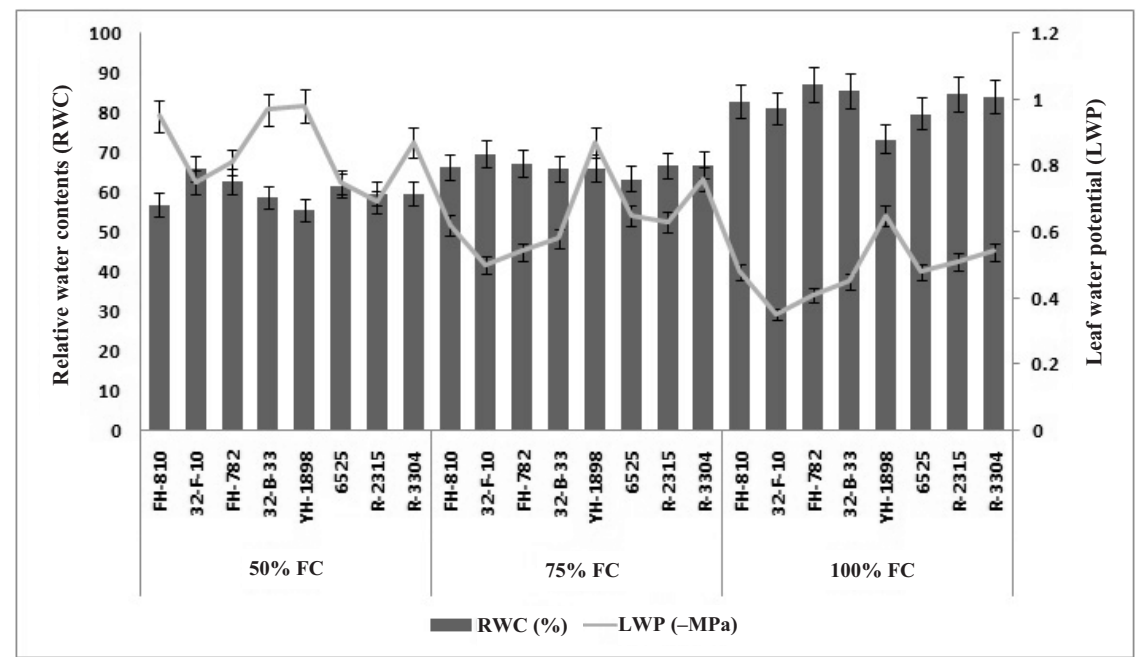

Figure 3. Influence of drought stress on relative water contents (RWC) and leaf water potential (LWP) in maize hybrids (mean of three replicates \pm S.E.). Field capacity (FC) levels: $100 \% \mathrm{FC}, 75 \% \mathrm{FC}$ and $50 \% \mathrm{FC}$

Photosynthetic activity (A), stomatal conductance $\left(g_{S}\right)$ and transpiration rate (E)

Since the A was retarded with increasing drought levels, highest A was achieved by $32-\mathrm{F}-10$ followed by 6525 and FH-810 at 100\% FC (Fig. 4). While moisture contents at $75 \%$ and $50 \%$ FC reduced A of all hybrids significantly. Among hybrids, 32-F-10 again was superior with improved A at 75\% FC and was at par with 6525 and $\mathrm{FH}-810$ at $100 \%$ FC. The highest reduction in A was exhibited by YH-1898 at $75 \% \mathrm{FC}$, nonetheless similar performance was observed in hybrid 32-B-33, YH-1898, R-3304 at 50\% FC. Regarding $\mathrm{g}_{\mathrm{s}}$, it was noted that at $100 \% \mathrm{FC}, 32-\mathrm{F}-10$ and R-3304 showed higher $\mathrm{g}_{\mathrm{s}}$ while other hybrids were noted to have less $\mathrm{g}_{\mathrm{s}}$, keeping FH-810 at the end. In mild drought (at 75\% FC) highest $g_{s}$ was observed by 32-F-10, FH-782 and R-3304 while minimum by FH-810 and YH-1898. Moreover, at 50\% FC 32-F-10 and 6525 showed an evidence of the highest $\mathrm{g}_{\mathrm{s}}$ while 32-B-33 was the hybrid to develop least $\mathrm{g}_{\mathrm{s}}$ as elaborated in the graphical representation (Fig. 5). Further, E was much more at $100 \%$ FC started to decline at $75 \%$ FC and become much lesser at 50\% FC (Fig. 6). It was noticed that in context to $\mathrm{g}_{\mathrm{s}}$, E was also decreased with decreasing soil moisture. Among hybrids, 32-F-10 exhibited higher E at all FC levels while FH-742, 6525 and R-3304 showed statistically same E, however FH-819, R2315 and 32-B-33 scored statistically same E at 100\% FC. Hybrid YH-1898 exhibited least $\mathrm{E}$ at all FC levels (Fig. 6). 


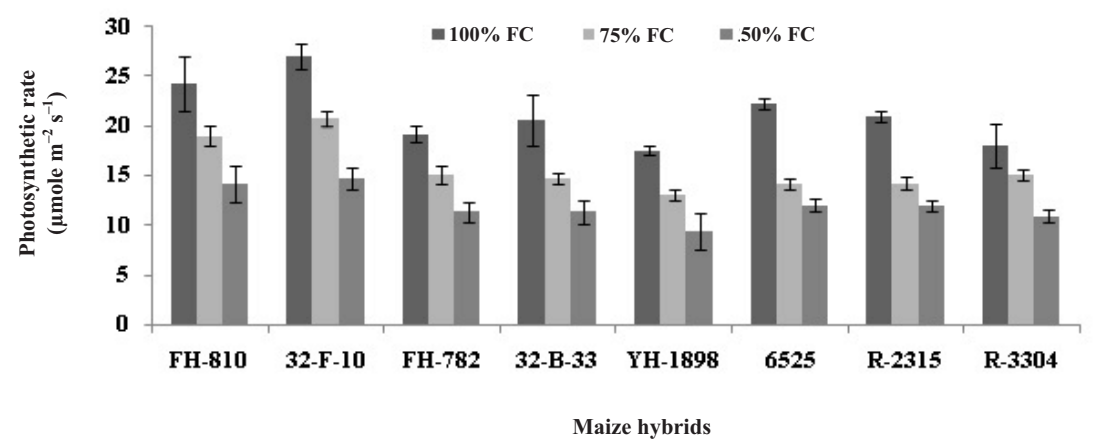

Figure 4. Influence of drought stress on photosynthetic rate (A) in maize hybrids (mean of three replicates \pm S.E.). Field capacity (FC) levels: $100 \%$ FC, $75 \%$ FC and $50 \%$ FC

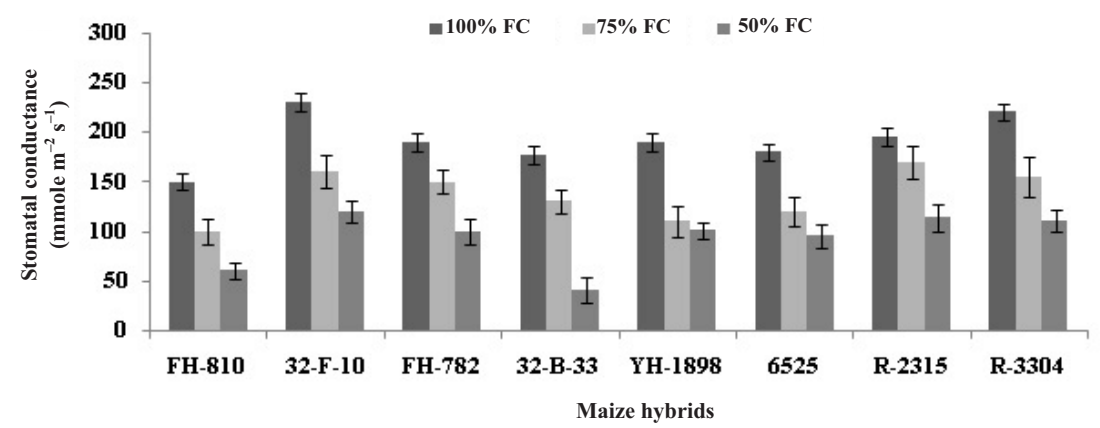

Figure 5. Influence of drought stress on stomatal conductance (gs) in maize hybrids (mean of three replicates \pm S.E.). Field capacity (FC) levels: $100 \%$ FC, $75 \%$ FC and $50 \%$ FC

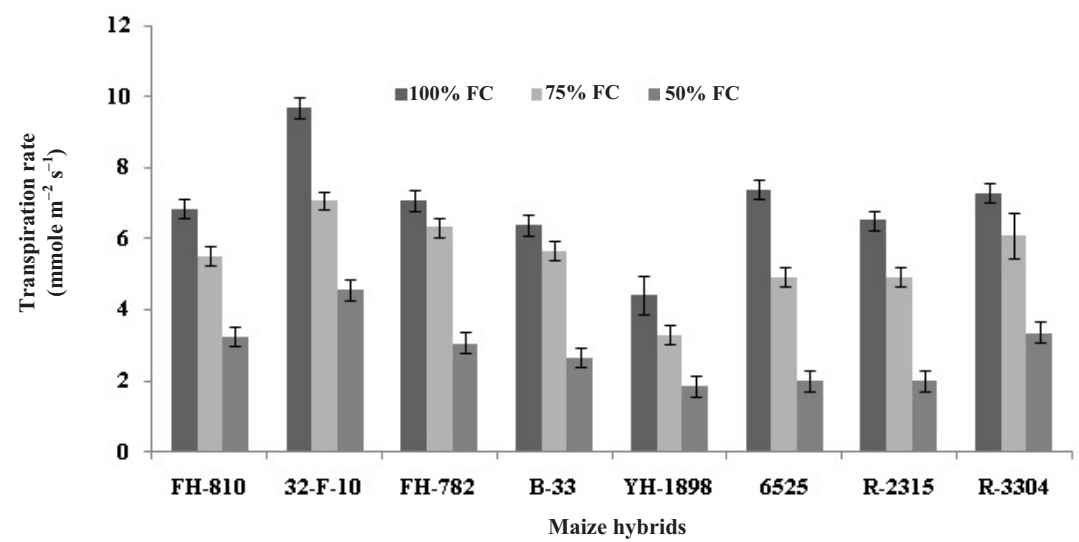

Figure 6. Influence of drought stress on transpiration rate (E) in maize hybrids (mean of three replicates \pm S.E.). Field capacity (FC) levels: $100 \%$ FC, $75 \%$ FC and $50 \%$ FC 


\section{Discussion}

Drought is one of abiotic stresses that depends upon stochastic weather conditions rather than other static stresses, included salinity, flooding and specific ion toxicity. In our study, the maize hybrids and water deficit levels interaction was quite significant. An obvious difference of plant height was observed as in the best performing maize hybrid 32-F-10 and other hybrids (Fig. 1). This might be attributed to non-availability of water for photosynthesis and resulted in reduced growth. In addition, it might also be ascribed to less absorption of water and nutrients from soil. These results are confirmed by Olaoye et al. (2009) who reported that 24 days after sowing $100 \%$ FC increased the plant height of maize hybrids up to $45.38 \mathrm{~cm}$ and decreasing FC reduced the plant height. Sah and Zamora (2005) found that water stress significantly reduced the plant height at vegetative stage. Water deficit arrested the growth of plant via altering phenology and development of plant to considerable level. In our study, the reduction in leaf length was attributed to the non-provision of water to photosynthetic mechanism (Fig. 2). Attainment or shrivelling of stem diameter is function of change in internal water status of plant (Simonneau et al. 1993). This kind of changes in stem diameter was correlated with predawn LWP in the prolonged situation of drought (Katerji et al. 1994). Further, it is evident from our study that there was a significant effect of drought on stem diameter of maize hybrids. Yatapanage and So (2001) used the stem diameter as an important trait to determine the LWP in sorghum (Sorghum bicolor L.). Acevedo et al. (1971) affirmed that maize leaves elongation was greatly sensitive to minute reduction in soil and leaf water potential. The reduction in leaf area by severe drought at vegetative stage in maize plant was also supported by Ali et al. (2011). Moreover, Olaoye et al. (2009) indicated that highest leaf area was recorded at $100 \% \mathrm{FC}$. He concluded that decrease in $\mathrm{FC}$ resulted in reduction of the leaf area of maize hybrids significantly. Abo-El-Kheir and Mekki (2007) reported that stress intensity has its own effect on leaf area. The reduction in leaf area by severe drought was also supported by Ali et al. (2011). Actually all assimilates from shoot move toward the root to cope against the drought.

Increase in leaf temperature reduces the LWP, RWCs and E of plants. The first and the most important effect of drought on the growth of plant body is the obstructed leaf water budget (Farooq et al. 2010). Medici et al. (2003) reported the more LWP in well-watered treatment and decreased in moisture deficit condition. The same has been studied in the present research activity where with the reducing FC, LWP also reduced subsequently (Fig. 3). During the drought stress the reduction in $\mathrm{g}_{\mathrm{s}}$ was the first and the primary reason behind decline of A (Cornic 2000). Literature cited that on increasing the severity of drought stress dehydration occurred and lead to metabolic impairment (Anjum et al. 2011b). In the current study, it had been found that with the decrease in FC, A and $\mathrm{g}_{\mathrm{s}}$ was severely hampered as well (Figs 4, 5). Moreover, A can be retarded either by closure of stomata and movement of $\mathrm{CO}_{2}$ to mesophyll cells (Anjum et al. 2011d). Mild stress had less deleterious effect on A as compared to severe drought stress (Fig. 4). Such results have been supported by Zhou et al. (2007), who manifested a substantial decrease in FC led to reduction in photosynthate synthesis. Inhibition of photosynthesis disturb the equi- 
librium between the ROS and antioxidants defense (Reddy et al. 2004) as a result of which deposition of ROS take place in the cell, thus concomitant with the oxidative damage. The reduction in photosynthetic leaf area by water deficit stress reduces the efficiency of plant to generate dry matter. In the present study, it was found that increasing drought stress decreased $g_{s}$ (Fig. 5). This might be ascribed to adaptive mechanism of plant to reduce the loss of water. This might be due to adaptive feature of plant to save water. It has been studied that development of stomata has been considered an important development in its evolution (Brodribb and McAdam 2011). They are environmentally controlled entrances into the plants that control $\mathrm{CO}_{2}$ uptake and transpiration from plant. They are also responsible for photosynthesis and nutrient uptake (Farooq et al. 2009). Increase in $\mathrm{g}_{\mathrm{s}}$ enhances the $\mathrm{CO}_{2}$ diffusion into leaf blade and favours higher photosynthesis which in turn produces higher biomass and more crop yield. Transpiration (E) from leaf surface lowers the leaf temperature and higher stomatal conductance increases cooling of leaf. Closure of stomata helps the plant to maintain high leaf water contents but leads to lower down photosynthetic activity. Drought tolerant cultivars have deeper and thick roots. The thick roots are positively correlated with xylem vessel area, which are vital to the conductance of water from soil to the upper parts of the plants to meet the evaporative demand. Therefore, it is concluded that drought stress adversely affected the morphological and physiological traits of all maize hybrids under study. However, among the grown maize hybrids 32-F-10 performed best regarding the studied traits in all the three drought treatments of well watered $(100 \%$ FC), mild drought $(75 \%$ FC) and severe drought $(75 \% \mathrm{FC})$ conditions. On the other hand, the maize hybrid YH 1898 was noted highly drought sensitive. Thus, from these results, it is affirmed that hybrid 32-F-10 can be employed for further breeding to improve drought tolerance. Moreover, screening at initial vegetative stages and recording morphologial and physiological traits are seemed to more productive, informative and time saving in order to screen various genotypes to improve drought tolerance.

\section{References}

Abo-El-Kheir, M.S.A., Mekki, B.B. 2007. Response of maize single crass-10 to water deficits during silking and grain filling stages. World J. Agric. Sci. 3:269-272.

Acevedo, E., Hasio, T.C., Henderson, D.W. 1971. Immediate and subsequent growth response of maize leaves to changes in water status. Plant Physiol. 48:631-636.

Ali, Z., Basra, S.M.A., Munir, H., Mahmood, A., Yousaf, S. 2011. Mitigation of drought stress in maize by natural and synthetic growth promoters. J. Agric. and Social Sci. 7:56-62.

Anjum, S.A., Farooq, M., Wang, L.C., Xue, L.L., Wang, S.G., Wang, L., Chen, M. 2011a. Gas exchange and chlorophyll synthesis of maize cultivars are enhanced by exogenously applied glycinebetaine under drought conditions. Plant, Soil Environ. 57:326-331.

Anjum, S.A., Wang, L.C., Farooq, M., Hussain, M., Xue, L.L., Zou, C.M. 2011b. Brassinolide application improves the drought tolerance in maize through modulation of enzymatic antioxidants and leaf gas exchange. Journal of Agronomy and Crop Science 197:177-185.

Anjum, S.A., Xie, X.Y., Farooq, M., Wang, L.C., Xue, L.L., Shahbaz, M., Salhab, J. 2011c. Effect of exogenous methyl jasmonate on growth, gas exchange and chlorophyll contents of soybean subjected to drought. African J. of Biotechnol. 10:9640-9646.

Anjum, S.A., Xie, X.Y., Wang, L.C., Saleem, M.F., Man, C., Lei, W. 2011d. Morphological, physiological and biochemical responses of plants to drought stress. African J. of Agric. Res. 6:2026-2032. 
Athar, H.R., Ashraf, M. 2005. Photosynthesis under drought stress. In: Pessarakli, M. (ed.), Handbook of Photosynthesis. Taylor and Francis. New York, USA, pp. 793-804.

Brodribb, T.J., McAdam, S.A.M. 2011. Passive origins of stomatal control in vascular plants. Science 331:582-585.

Cornic, G. 2000. Drought stress inhibits photosynthesis by decreasing stomatal aperture: Not by affecting ATP synthesis. Trend in Plant Sci. 5:187-188.

Delachiave, M.E.A., De Pinho, S.Z. 2003. Germination of Senna occidentalis link: Seed at different osmotic potential levels. Brazilian Archives of Biol. and Technol. 46:163-166.

Duvick, D.N. 2005. The contribution of breeding to yield advances in maize (Zea mays L.). Advances in Agron. 86:83-145.

Farooq, M., Basra, S.M.A., Wahid, A., Cheema, Z.A., Cheema, M.A., Khaliq, A. 2008. Physiological role of exogenously applied glycinebetaine in improving drought tolerance of fine grain aromatic rice (Oryza sativa $\mathrm{L}$.) J. of Agron. and Crop Sci. 194:325-333.

Farooq, M., Wahid, A., Cheema, S.A., Lee, D.J., Aziz, T. 2010. Comparative time course action of foliar applied glycinebetaine, salicylic acid, nitrous oxide, brasinosteroids and spermine in improving drought resistance of rice. J. of Agron. and Crop Sci. 196:336-345.

Farooq, M., Wahid, A., Kobayashi, N., Fujita, D., Basra, S.M.A. 2009. Plant drought stress, effects, mechanisms and management. Agron. for Sustainable Development 29:185-212.

Food and Agriculture Organization (FAO) of the United Nations. 2012. FAOSTAT. Food and Agricultural Commodities Production. Rome, Italy.

Hoekstra, F.A., Golonina, E.A., Buitink, J. 2001. Mechanism of plant desiccation tolerance. Trends in Plant Sci. 6:431-438.

Karrou, M., Maranville, J.W. 1995. Response of wheat cultivars to different soil nitrogen and moisture regimes: II. Leaf water content, stomatal conductance and photosynthesis. J. Plant Nutr. 4:777-791.

Katerji, N., Tardieu, F., Bethenod, O., Quetin, P. 1994. Behavior of maize stem diameter during drying cycles: Comparison of two methods for detecting water stress. Crop Sci. 34: 165-169.

Medici, L.O., Machado, A.T., Azevedo, R.A., Pimentel, C. 2003. Glutamine synthetase activity, relative water content and water potential in maize submitted to drought. Biol. of Plant 47:301-304.

MSTAT Development Team. 1989. MSTAT user guide: A microcomputer programme for the design management and analysis of agronomic research experiments. Michigan State University, East Lansing, USA.

Nachabe, M.H. 1998. Refining the definition of field capacity in the literature. J. of Irrigation and Drainage Engineering 124:230-232.

Olaoye, G., Menkir, A., Ajala, S.O., Jacob, S. 2009. Evaluation of local maize (Zea mays L.) varieties from Burkina Faso as source of tolerance to drought. J. Appl. Biosci. 17:887-898.

Reddy, A.R., Chaitanya, K.V., Vivekanandan, M.V. 2004. Drought induced response of photosynthesis and antioxidants metabolism in higher plants. J. Plant Physiol. 161:1189-1202.

Sah, S.K., Zamora, O.B. 2005. Effect of water deficit at vegetative and reproductive stages of hybrid, open pollinated variety and local maize (Zea mays L.). J. of Institute of Agric. and Animal Sci. 26:37-42.

Simonneau, T., Habib, R., Goutouly, J.P., Buguet, J.G. 1993. Diurnal changes in stem diameter depend upon variation in water content: Direct evidence from peach trees. J. Exp. Bot. 44:615-621.

Somerville, C., Briscoe, J. 2001. Genetic engineering and water. Science 292:2217.

Steel, R.G.D., Torrie, J.H., Dickey, D.A. 1997. Principals and Procedures of Statistics. A biometrical approach. 3. ed. McGraw-Hill Inc Book Co. New York, USA, pp. 352-358.

Tambussi, E.A., Bort, J., Araus, J.L. 2007. Water use efficiency in $\mathrm{C}_{3}$ cereals under Mediterranean conditions: A review of physiological aspects. Ann. Appl. Biol. 150:307-321.

Wang, W., Vinocur, B., Altman, A. 2003. Plant responses to drought, salinity and extreme temperature: towards genetic engineering for stress tolerance. Planta 218:1-14.

Yatapanage, K.G., So, H.B. 2001. The relationship between leaf water potential and stem diameter in sorghum. Agron. J. 93:1341-1343.

Zhou, Y., Lam, H.M., Zhang, J. 2007. Inhibition of photosynthesis and energy dissipation induced by water and high light stresses in rice. J. Exp. Bot. 58:1207-1217. 